\title{
Mia Couto: viajante e afinador de identidades
}

\author{
Mia Couto: traveler and tuner of identities
}

\author{
ORQUíDEA MARIA MOREIRA RIBEIRO \\ FERNANDO ALBERTO TORRES MOREIRA \\ Universidade de Trás-os-Montes e Alto Douro
}

Resumo: A identidade cultural moçambicana forja-se pela força do diálogo e da articulação funcional de diferentes identidades. Neste particular, a obra de Mia Couto destaca-se pelo modo único como congrega a riqueza desse mecanismo, afirmando-se como um interlocutor original no processo de construção da identidade nacional para o qual concorrem diversos elementos identitários que formam a especificidade moçambicana no conjunto da africanidade.

Viajante do tempo, Mia Couto faz a história (e a identidade) moçambicana pela soma de um enorme conjunto de estórias, marca de um conhecimento ancestral que se revela necessário para a construção de um novo paradigma identitário - uma identidade que se constrói no compromisso entre o passado e o presente - que o autor vai afinando em cada nova obra porque se reconhece como "mulato de existências" que anseia pela esperança do futuro.

Palavras-chave: Moçambique; Mia Couto; Identidade; Tradição; Hibridismo

\begin{abstract}
Mozambique's cultural identity is forged by the force of dialogue and functional articulation of different identities. In this regard, Mia Couto's work is distinguished by the unique way he brings together the wealth of this mechanism, asserting itself as an original party in the national identity building process to which many identity elements contribute to form the Mozambican specificity in set of Africanness.

Time traveler, Mia Couto makes Mozambican history (and identity) summing up a huge set of stories, marks of an ancestral knowledge that proves necessary for the construction of a new identity paradigm - an identity that is built on a compromise between past and present - that the author tunes in each new work because he is recognized as "mulatto of existences" that yearns for future hope.
\end{abstract}

Keywords: Mozambique; Mia Couto; Identity; Tradition; Hybridity

"A identidade de um povo é feita por um somatório de identidades individuais, colectivas, religiosas, de grupos, de raças, etc. (...) A ideia é que a identidade é uma moldura, mas essa moldura tem de dar espaço a diversidades. Portanto, quando falamos de uma identidade temos que falar sempre no plural, porque se estou à procura de uma identidade pura vou cair sempre no erro."

Mia Couto, Entrevista (2007)

"a nossa essência é a nossa história comum, as nossas sociedades, por muito diferentes que pareçam, partilham o mesmo confronto entre a utopia de podermos renascer das cinzas e a frustração de carregarmos um passado demasiado pesado."

MiA Couto, Entrevista (2009b)

"As identidades culturais não são rígidas nem, muito menos, imutáveis. São resultados transitórios e fugazes do processo de identificação." 
Segundo Homi Bhabha, "The enunciation of cultural difference problematizes the division of past and present, tradition and modernity, at the level of cultural representation and its authoritative address (...) [and] we should remember that it is the "inter" - the cutting edge of translation and negotiation, the in-between, the space of the enter (...) that carries the burden of the meaning of culture" (BHABHA, 1995, p. 207). É esta problematização entre passado e presente, entre tradição e modernidade, bem notória nas suas obras, que orienta a reflexão de Mia Couto na busca do estabelecimento da identidade cultural moçambicana.

Consciente de que uma identidade cultural se forja no diálogo e articulação funcional de diferentes identidades, Mia Couto configura a ideia de nação na sua narrativa ficcional, instituindo-se como um interlocutor que, na esteira de Bhabha, sabe que "a identidade é reivindicada a partir de uma posição de marginalidade" (BHABHA, 1998, p.247). A sua opção recai numa narração de costumes que se vai afinando a cada nova narrativa, numa acumulação de histórias somadas de que os velhos personagens são fiéis depositários e que existem apenas enquanto elementos culturais para ajudar à (re)construção da moçambicanidade, agora em novo paradigma, como bem observou Carlos Baptista Bach quando afirma que “Em 'Terra Sonâmbula' nota-se que o conhecimento ancestral é necessário para que se possa construir um novo paradigma" (BACH, 2008, p. 3).

Por isso é que Mia Couto, crente na necessidade de um compromisso entre passado e presente e na sua autodesignação de "mulato não de raças, mas de existências" (COUTO, 1987, p. 85), conta as suas histórias apostando no hibridismo cultural, na miscigenação identitária tão caros a Pecora e a Spivak (SPIVAK, 1999, p. 155) e no entre-lugar lançado por Bhabha, como solução para a problemática da identidade da nação moçambicana.

Os romances de Mia Couto demonstram a pluralidade cultural (e étnica) de Moçambique e provam o carácter de mosaico da identidade do país; enquanto palavra escrita são isso mesmo, já que combinam, numa "harmonia híbrida", o novo com o antigo, o oral e o escrito, apresentando a língua escrita como afinadora maior da oralidade.

André Cristiano José salienta que "longe de (re)criar identidades essencialistas, cristalizadas no tempo e no espaço, Mia Couto é fiel à historicidade, complexidade e dinâmicas que lhes são próprias" (JOSÉ, 2008, p. 151). A proposta de Mia Couto para a construção da identidade moçambicana é, portanto, a miscigenação cultural que ele materializa no seu discurso linguístico de poeta que conta estórias mas que escreve em prosa, numa escritoralidade (que ressuma o velho e o novo) única que bem pode ser a marca de água identitária fracturante e necessária à ideia de nação, uma tarefa só ao alcance de um "contrabandista entre dois mundos", como o próprio se define ao jornal brasileiro A Folha de S. Paulo (18 de Novembro 1998). Trata-se de uma re-invenção da moçambicanidade que exclui uma demarcação nítida entre história e ficção, um processo durante o qual "myth blends with history and fantasy with reality" (AFOLABI, 2001, p. 118). Talvez o seu próprio hibridismo enquanto escritor - mistura de poeta, jornalista e contador de histórias - tenha colocado Mia Couto numa posição privilegiada para o desempenho desta tarefa de construtor e afinador de identidades (uma mistura de sonho, realidade e fantasia) e ser, por isso, um "regenerative writer" como o define Afolabi (AFOLABI, 2001, p. 119), um "cronista da experiência moçambicana contemporânea", alguém que "trabalha a modernidade sem virar as costas ao património cultural", tal como o vê o compatriota Nelson Saúte, preocupado com "as tradições, a diversidade cultural, o domínio da oralidade" (SAÚTE, 1991a, p.10). Mia Couto sabe que cada moçambicano, aliás como ele próprio, é um constructo cultural, um produto de várias culturas endógenas, de moçambicanidade e também de culturas exógenas, e, consciente como está desta realidade, o seu objectivo enquanto construtor da identidade é consolidar o legado memorial de Moçambique; ele é um "pessimista com esperanças" (COUTO, 1994, p. 15) que luta contra o esquecimento em favor da memória, que denuncia bem alto esse consenso silencioso, mas ensurdecedor, que quer apagar a história recente do seu país e assim limitá-lo na sua identidade.

Um dos propósitos essenciais de Mia Couto é alimentar a esperança (que nele é incessante) de que o povo moçambicano preserve os aspectos culturais que suportam a sua identidade; esta preservação vai no sentido de uma identificação com os sinais culturais produzidos que habitam o imaginário das pessoas, um imaginário que não apenas é preenchido com elementos da tradição cultural moçambicana, mas também com novos elementos identitários resultantes do contacto com outras culturas. $\mathrm{O}$ escritor sabe, na esteira de um Stuart Hall, que

$$
\begin{aligned}
& \text { uma cultura nacional é um discurso - um modo de } \\
& \text { construir sentidos que influencia e organiza tanto } \\
& \text { as nossas acções quanto a concepção que temos de } \\
& \text { nós mesmos (...) As culturas nacionais, ao produzir } \\
& \text { sentidos sobre 'a nação', sentidos com os quais } \\
& \text { podemos nos identificar, constroem identidades. Esses } \\
& \text { sentidos estão contidos nas histórias que são contadas } \\
& \text { sobre a nação, memórias que conectam o seu presente } \\
& \text { com o seu passado e imagens que dela são construídas } \\
& \text { (HALL, 2005, p. 50-51). }
\end{aligned}
$$

Contribuir para a construção de uma identidade moçambicana, de uma ideia de nação, é um objectivo 
claro e assumido por Mia Couto, como se de uma viagem se tratasse, uma viagem em busca (e construção) de um espírito de nação; essa intenção está bem explícita e enunciada numa entrevista concedida a Michel Laban onde o autor caracteriza Moçambique como um país "muito comprido e a estrada é o único factor que liga, que faz com que o país circule dentro de si próprio e Moçambique tem de viajar dentro de si próprio para ser um país" (COUTO apud LABAN, 1996, p. 117); de igual modo, esse propósito surge num comentário que o escritor fez sobre o seu romance Terra Sonâmbula que descreve como "um livro de viagem, é um livro de procura de identidade" (COUTO apud SILVA, 1997, p. 04'). Percebese porquê: em Terra Sonâmbula as personagens são microcosmos paradigmáticos dessa busca por uma estrada simbólica, com particular destaque para Muidinga, que nasce de novo, assume uma outra identidade, ao saberse, identificar-se como Gaspar; mas este nascimento, ou deveríamos dizer renascimento, mais não é do que a confirmação da estratégia coutiana com vista à construção identitária: Moçambique, precisa de se (re)conhecer, de celebrar a tradição como base do futuro, tal como o fez o jovem Muidinga que, pela leitura dos cadernos de Kindzu reencontra as tradições do seu povo e se reencontra também como Gaspar, um ser todo ele marcado por/ resultado de uma cultura tradicional e de um passado colonialista ${ }^{2}$. Também Ermelindo Mucanga, o morto/ personagem de A Varanda do Frangipani (1996), na sua breve incursão de seis dias à vida por pessoa interposta, queria lembrar o passado, recuperar a memória, no fundo, do mesmo modo que Muidinga, aspira a uma identidade que já não reconhece; e o problema é exactamente esse porque, como afirma Marta Gino, personagem do mesmo romance, "O verdadeiro crime que está a ser cometido [em Moçambique] é que estão a matar o antigamente" (COUTO, 1996, p. 59), e daí que "Há que guardar este passado senão o país fica sem chão" (COUTO, 1996, p. 103), um chão que sustenta identitariamente o país, que está na sua matriz cultural, um chão de que os velhos são a terra: "Mas são pessoas [os velhos], são o chão desse mundo que você pisa lá na cidade" (COUTO, 1996, p. 78). ${ }^{3}$ Mas Marta chega ainda a uma outra conclusão definitiva sobre a identidade moçambicana: "Nessa altura

\footnotetext{
SILVA, Ana Cláudia da. Um café com Mia Couto. Entrevista com Mia Couto (não publicada). São Paulo: 1997. Fotocópia gentilmente cedida pela autora e entrevistadora a Susana Ramos Ventura. (VENTURA, 2013, p. 221)

2 Cabe aqui referir as palavras do escritor chileno Luís Sepúlveda no programa da RTP1 Câmara Clara em 15/11/09 onde declarou só ter percebido o conceito de africanidade após a leitura de Terra Sonâmbula

3 Maria Alzira Seixo caracteriza A Varanda do Frangipani deste modo: "um livro sobre as identidades culturais, não encaradas no absoluto do seu isolamento e de um nacionalismo redutor, mas através da experiência histórica, mesmo dramática ou castradora, que a assunção dos tempos instituiu de forma indelével” (SEIXO, 2001, p. 359)
}

eu não sabia que, bem vistas as contas, todos nós somos mulatos. Só que, em alguns, isso é mais visível por fora" (COUTO, 1996, p. 131).

O processo de reconstrução identitária está bem patente, de igual modo, em $O$ Voo do Flamingo (2000). Máximo Risi, o representante da ONU, tem de aprender o que é a africanidade porque, como muito bem intui, " $\mathrm{O}$ que eu não entendo é este mundo daqui” (COUTO, 2000, p.42) e, por isso, "Não sabe pisar, não sabe andar neste chão" (COUTO, 2000: 70) e tem de aprender a caminhar naquela terra em que os pés terreiam e acariciam o infinito do chão (COUTO, 2000, p. 53), tem de saber que em Moçambique "a terra é um ser [que] carece de família, desse tear de inexistências a que chamamos ternura" (COUTO, 2000, p. 114); o tradutor/narrador também sofre um processo de aprendizagem porque, tal como o povo, "(...) andava bastante confuso com o tempo e a actualidade" (COUTO, 2000, p. 26); formado nas artes de ler e escrever porque estudou em escola, o tradutor tem um problema de fundo: "aquilo que sabe tem pouca idade" (COUTO, 2000, p. 140) nas palavras de seu pai Sulplício, faltando-lhe a substância do tempo. Mais: lembra-se do passado, do que se passou antigamente, "mas não sabe de nada" (COUTO, 2000, p. 140) porque, como bem lhe ensina o velho pai, "na nossa terra, um homem é todos os outros" (COUTO, 2000, p. 144) e, por isso, é preciso ouvir a terra que "(...) guarda a raiz da gente"( COUTO, 2000, p. 204).

Marianinho, protagonista de Um Rio Chamado Tempo, uma Casa Chamada Terra (2002), é um reinventor da identidade cultural, começando por resgatar o passado, as tradições, enquanto parte do processo que conta também com a negociação com novas culturas.; ele próprio pertence a uma cultura híbrida e é o exemplo acabado do trabalho de costura feito por Mia Couto pela simbiose entre oralidade/tradição e a escrita/modernidade num balanço constante em que o intervalo entre os dois pares carece de ser cerzido continuamente. Marianinho vive um processo de tradução cultural, vive o entre-lugar e é o portador de uma nova cultura: a sua identidade compõese pela tradição e pela modernidade dos seus valores e, no final da sua construção identitária, quando se assume como o esteio de Nyumba-kaya, ele é definitivo para com o tio Ultímio que quer comprar a casa: "porque essa casa sou eu mesmo. O senhor vai ter que me comprar a mim para ganhar posse da casa. E para isso, Tio Ultímio, para isso nenhum dinheiro é bastante" (COUTO, 2002, p. 249). Marianinho dava assim sentido final à frase/epígrafe que o autor atribuiu a Dito Mariano: "O importante não é a casa onde moramos. Mas onde em nós a casa mora" (COUTO, 2002, p. 53). O jovem Mariano não fica na casa, mas ela fica a morar nele enquanto espaço simbólico de valores histórico e culturais. Nyumba-Kaya, aliás Marianinho, 
tornou-se o exemplo do hibridismo cultural que enforma a moçambicanidade.

Em Jesusalém (2009a), Mia Couto reafirma o hibridismo cultural e o insustentável peso do passado na construção do futuro. Como esclareceu, "Neste livro, está presente a impossibilidade de renascermos do zero e da absoluta negação do que já fomos" (COUTO, 2009b, s/p.). Silvestre Vitalício quis fazer tudo isso, quis viver na desmemória, despir-se da identidade, construir tudo de novo, cortando rente com o passado; criou-se Deus e, como tal, quis criar o seu mundo, Jesusalém, um espaço iniciático, fechado ao movimento, para um homem novo sem a memória do passado e, desde logo, como nova identidade, como se depreende pelas palavras de Mwanito: "Quando nos mudámos para Jesusalém, meu pai nos conferiu outros nomes. Rebaptizados, nós tínhamos outro nascimento. E ficávamos mais isentos do passado" (COUTO, 2009a, p. 41) A realidade identitária de Jesusalém era bem simples: "Se não há passado, não há antepassados" (COUTO, 2009a, p. 43) Jesusalém é um mundo outro, sem história nem memória, um lugar de mortos/vivos que não têm viagem, parados no tempo. Mas a tentativa de renascer do zero e renegar o passado memorial falhou desde o início porque a memória de Dordalma é convocada a todo o instante, e Silvestre Simplício que fora um bom contador de histórias tornouse uma caricatura, uma história mal contada no dizer do seu filho mais novo (COUTO, 2009a, p. 72).

Viver no lugar do esquecimento não é possível porque o homem é fruto de uma inscrição no tempo; e Marta, a portuguesa que vem em busca de memórias e espoleta as memórias dos habitantes de Jesusalém, alertou Silvestre: "Não se pode esquecer tudo tanto tempo. Não existe viagem assim tão longa" (COUTO, 2009a, p. 171) A mensagem é clara: a identidade não se constrói no esquecimento ou nos silêncios consensualizados sobre o passado; haverá sempre um momento em que a travessia do silêncio é interrompida pelo ruído da história, pela paisagem que a viagem identitária fixou. A obra de Mia Couto inscreve-se neste percurso, traduzindo mestiçagens que se interpenetram, expondo a diversidade cultural que compõe o país assim afinando o estabelecimento da moçambicanidade certo de que, como escreveu em Terra Sonâmbula, "escrever é ensinar alguém a sonhar" (COUTO, 1992, p. 73).

$\mathrm{Na}$ esteira da herança legada por José Craveirinha, que engendrou nos seus poemas um espaço de africanidade onde "ibéricas heranças de fados e broas / se africanizaram para a eternidade nas minhas veias" (CRAVEIRINHA, 1982, p. 107), Mia Couto é crente de que a identidade moçambicana é o resultado de trocas de memórias e, por isso, se constrói sobre os problemas que vieram do passado colonial, da guerra pela independência, da guerra civil que se lhe seguiu, da nova "colonialidade do poder" (QUIJANO, 2000) pós 1992 e com a "confrontação do mosaico de vozes que constitui o universo cultural" do povo de Moçambique, projectando "para o país e para o mundo, uma ideia de moçambicanidade e de cidadania" (JOSÉ, 2008, p. 151).

Para André José, “em Mia Couto a oscilação pendular entre múltiplos elementos identitários resulta na criação de uma dinâmica identitária própria, moçambicana" (2008, p. 155). A estratégia de construção identitária em Mia Couto apoia-se sempre no passado (= tradição) e no futuro, emblematicamente representados por personagens idosas e por crianças ou jovens que se confrontam, que conflituam entre si mas que, no final, espelham um compromisso necessário. Em Terra Sonâmbula (1992) temos o par Tuahir/Muidinga, em A Varanda de Frangipani (1996) temos os velhos e Marta Gino, em $O$ Último Voo do Flamingo (2000) o jovem tradutor e o seu velho pai, em Um Rio Chamado Tempo, Uma Casa Chamada Terra (2002) o velho Mariano e o seu filho/neto Marianinho e, finalmente, em Jesusalém (2009a) Silvestre Simplício e o seu filho Mwanito. Todos estes velhos, como deixa bem expresso Marta Gino de $A$ Varanda de Frangipani, "não são apenas pessoas (...) são guardiões de um mundo. É todo esse mundo que está sendo morto" (COUTO apud MACHAVA, 2007, p.57). Esta frase exprime, a um tempo, a constatação de uma realidade e uma preocupação constantes de Mia Couto: o papel das tradições, das raízes culturais ancestrais do povo, por um lado e, por outro, a importância dessas tradições para a construção do presente e de uma identidade futura que se pretende recupere as experiências do passado 4 dentro da "diversidade de matrizes culturais que informam o país" (JOSÉ, 2008, p. 151). O próprio autor, repetidamente, mostra o seu sentimento pela desvalorização dos velhos (e crianças), o mesmo é dizer dos improdutivos, no tempo presente, em diversas entrevistas:

Mia Couto explica que

a ideia de que, em África, os velhos são sempre respeitados resulta de uma mistificação. Isso nem sempre sucede, mesmo em sociedades que não foram desarrumadas pela colonização. Subsiste na visão sobre a África ainda uma ideia cor-de-rosa, certa romantização do "bom selvagem". Mas é verdade que, em certas sociedades - e muitas delas estão vivas em Moçambique - o lugar dos mais velhos é fonte de prestígio e saber (...) Essa tradição está sendo reconstruida pela actualidade. A modernidade

\footnotetext{
4 Vários autores, como, por exemplo, Ungulani Ba Ka Khosa, têm demonstrado a sua preocupação com as questões da identidade no período pós-independência em Moçambique, já que o espaço identitário foi "abafado", e alguns valores culturais perderam-se devido à diminuição de interesse pela tradição cultural (KHOSA, 2012, p. 202-203, 208).
} 
africana convive de modo atribulado com isso que chamamos de tradição e está refabricando rituais e crenças. Mas isso sucede num universo em que a miséria absoluta vai corroendo aquilo que antes era dominado pelo respeito. Num mundo ajoelhado perante a mercadoria, sucede na África aquilo que sucedeu em outros continentes: velhos e crianças estão desvalorizados porque produzem pouco e compram ainda menos (ZARUR, 2007) .

Não é difícil localizar a sabedoria dos velhos nos textos de Mia Couto e associar a expressão dessa sabedoria a práticas rituais, crenças, numa palavra, à tradição, ao passado cultural; os velhos são ao guardiães desse mundo tradicional, papel que o autor também reivindica para si, de um saber ancestral em que realidade e maravilhoso não raras vezes se confundem e são também a esperança existente para uma reconstrução identitária do povo moçambicano, projeto para o qual todos são convidados a participar até porque, percebe-se que Mia Couto, tal como Nelson Saúte, está convencido de que "povo que perde a sua identidade cultural, não tem mais nada para perder" (SAÚTE, 1991b, p.5). Mas esta cultura da tradicional oral já não circula como antes, já não há lugar para os contadores de histórias, para as reuniões ao fim da tarde à volta da fogueira ou debaixo de uma árvore para transmitir e receber os valores e o conhecimento, e é por isso que Mia Couto introduz a leitura (e a escrita) para fazer circular a tradição, as histórias dos velhos, os seus usos e costumes e fá-lo pela voz (leitura) dos mais novos, que sabem ler: Muidinga lê os cadernos de Kindzu, Mariano é o intérprete dos "testamentos" do avô, Mwanito escreve e lê para os mais velhos. Agora o tempo é outro, a história oral precisa ser escrita para ser preservada e renovada, e as histórias do estorinhador Mia Couto, qualificativo certeiro de Cecília Martins, "resgatam o imaginário ancestral moçambicano profundamente enraizado na oralidade" (COUTO apud MARTINS, 2002), já que na "desordem [após conflito] há a emergência de poderes tradicionais que pareciam estar enterrados no tempo" (COUTO apud SAÚTE 1991a, p. 10). Para Francisco Noa, "a componente da oralidade (...) funciona como substrato cultural e como factor constitutivo da identidade da literatura moçambicana" (NOA, 2008, p. 39).

Ao assumir a literatura como força interventiva e participante na construção da nação, Mia Couto instituise como viajante e construtor da mesma enquanto mediador que é da cultura oral e escrita e desempenha, em consequência, um papel ativo na preservação da memória colectiva. Para ele, como se verificou, a identidade forja-se, também, pelas pequenas histórias das pequenas coisas e dos homens comuns que vivem na marginalidade

\footnotetext{
5 Grifos nossos.
}

da grande História, mas que, no rasto e evolução do tempo são, no fim de contas, aquilo que confere a essência cultural a esta última; é o quotidiano, ilustrado e revelado pelas histórias simples que, no seu maravilhoso sonhado, é apresentado como verdadeiro alicerce de uma identidade que se sonha, que se deseja, sonhos e desejos que passam pela mudança, por novas vozes, por um novo tempo congregador para cuja estabilização a memória colectiva contribui.

Como se constata, Mia Couto assume, nos seus textos, o hibridismo como marca indelével das identidades que são sempre produto de várias misturas que o tempo opera numa dinâmica permanente. $\mathrm{O}$ escritor tem mesmo a certeza de que "A identidade é uma coisa que muda no tempo, dentro de nós próprios e, portanto, não é uma verdade pura e imutável" (COUTO apud MACHAVA, 2007). Consciente deste dinamismo das identidades, Mia Couto optou por nele participar, ao seu jeito, num esforço de afinação contínua, como a sequência das suas obras o comprova, e seguro de que o amanhã da identidade moçambicana, sendo também o que é hoje e todo um passado matricial enformador, é, de certeza, uma coisa diferente porque continuamente mutável. Ou, como afirmava o curandeiro de Terra Sonâmbula sobre o futuro de Moçambique e, claro, da sua identidade, "O problema não é o lugar (...) mas o caminho" (COUTO, 1996, p. 34).

É este caminho que Mia Couto quer ajudar a percorrer, a construir, estorinhando como Tuahir, estorinhando como só ele sabe, assumindo-se como terra dentro de cada pessoa, como alguém que anda a juntar os sonhos, a costurar os sonhos (COUTO, 1992, p. 197) porque, como muito bem lembrou em Raiz de Orvalho e outros Poemas, "Preciso ser um outro / para ser eu mesmo (...) Existo onde me desconheço / aguardando pelo meu passado / ansiando a esperança do futuro" (COUTO, 2009c, p. 13). Assim se afinam identidades, numa viagem contínua e no silêncio, essa língua de Deus (COUTO, 2003, p. 150) que o escrevinhador mediatiza nos seus textos, seguro de que, nas asas do flamingo, um novo dia se anuncia.

\section{Referências}

AFOLABI, Niyi. The Golden Cage. Regeneration in Lusophone African Literature and Culture. Trenton, NJ: Africa Word Press, Inc, 2001.

BACH, Carlos Batista. Sonhos de esperança em uma Terra Sonâmbula. In: Revista Nau Literária. Crítica e Teoria de Literaturas em Língua Portuguesa, Porto Alegre, v. 4, n. 1, 2008. Disponível em: <http://seer.ufrgs.br/index.php/NauLiteraria/ article/view/5808/3413>. Acesso em: 26 maio 2015.

BHABHA, Homi K. Cultural Diversity and Cultural Differences in the Post-colonial Studies Reader. London and New York: Routledge, 1995. 
BHABHA, Homi. O local da cultura. Belo Horizonte: URMG, 1998.

COUTO, Mia. A Varanda do Frangipani. Lisboa: Caminho, 1996.

COUTO, Mia. Entrevista. Mia Couto trata da Identidade como Essência Humana. Estadão de S. Paulo, 25 jun. 2009b. Disponível em: <http://www.rm.co.mz/index.php/programacao/ 88-arquivo/1406-mia-couto-trata-da identidade-como-essenciahumana>. Acesso em: 14 jun. 2015.

COUTO, Mia. Jesusalém. Lisboa: Caminho, 2009a.

COUTO, Mia. O voo do flamingo. Lisboa: Caminho, 2000.

COUTO, Mia. Pensatempos. Maputo: Editorial Ndjira, 2003.

COUTO, Mia. Raiz de Orvalho e outros Poemas. Lisboa: Caminho, 2009c.

COUTO, Mia. Terra Sonâmbula. Lisboa: Caminho, 1992.

COUTO, Mia. Um Rio Chamado Tempo, Uma Casa Chamada Terra. Lisboa: Caminho, 2002.

CRAVEIRINHA, José. "Ao meu pai ex-migrante". In: Karingana na Karingana. Lisboa/Maputo: Edições 70, 1982.

HALL, Stuart. A identidade cultural na pós-modernidade. Rio de Janeiro: DP\&A, 2005.

JOSÉ, André Cristino. "Revolução e Identidades Nacionais em Moçambique: diálogos (in)confessados”. In: RIBEIRO, Margarida Calafate; MENESES, Ana Paula (Org.). Moçambique. Das Palavras Escritas. Porto: Edições Afrontamento, 2008. p. 141-159.

KHOSA, Ungulani Ba Ka. Entrevista com Ungulani Ba Ka Khosa. In: LEITE, Ana Mafalda; KHAN, Sheila; FALCONI, Jessica; KRAKOWSKA; Kamila (Org.). Nação e Narrativa Pós.Colonial II. Entrevistas. Lisboa: Edições Colibri, 2012. p. 201-215.

LABAN, Michel.-Entrevista de Mia Couto recolhida por Michel Laban. In: QUINT, Anne-Marie (Ed.). La ville dans l'histoire et dans l'imaginaire, Centre de recherche sur les pays lusophones. Cahier $d u$ CREPAL, Presses Sorbonne Nouvelle, n. 3, p. 113-135, janvier 1996.

LEITE, Ana Mafalda. Empréstimos da Oralidade na Produção e Crítica Literárias Africanas. In: LEITE, Ana Mafalda. Oralidade \& Escritas na Literatura Africana. Lisboa: Colibri, 1998.

MACHAVA, Ricardo. Somos produto de várias misturas. Entrevista de Mia Couto a Ricardo Machava. O PAÍS - 26 jul. 2007. Disponível em: <macua.blogs.com/moambique.../ somos_produto_de_vrias_misturas_mia_couto.doc $>$. Acesso em: 14 jun. $201 \overline{5}$.

MARTINS, Cecília. O estorinhador Mia Couto: a poética da diversidade. Conversa com o escritor moçambicano no Funchal.
Revista Brasil de Literatura, Madeira, 2002. Disponível em: $<$ http://revistabrasil.org/revista/artigos/celina3.html >. Acesso em: 3 jun. 2015.

NOA, Francisco. Literatura Moçambicana. Os Trilos e as Margens. In: RIBEIRO, Margarida Calafate; MENESES, Ana Paula (Org.). Moçambique. Das Palavras Escritas. Porto: Edições Afrontamento, 2008. p. 35.

PECORA, Vincent. Nations and Identities: Classic Readings. Great Britain: Blackwell Publishers, 2001.

PERUZZO, Lisângela Daniele. Moçambique, duas visões: a representação da guerra e seus desdobramentos. Revista CRIOULA, n. 3, 2008. Disponível em: <http:/www.revistas. usp.br/crioula/article/viewFile/54017/57949>. Acesso em: 21 jun. 2015.

QUIJANO, Aníbal. Colonialidade del poder, eurocentrismo y América Latina. In: La Colonialidad del Saber: Eurocentrismo y Ciências Sociales - Perspectivas Latinoamericanas. Buenos Aires: CLASCO y UNESCO, 2000. Disponível em: <http:// bibliotecavirtual.clacso.org.ar/ar/libros/lander/quijano.rtf>. Acesso em: 22 jun. 2015.

SANTOS, Boaventura Sousa. Pela Mão de Alice. O social e o político na pós-modernidade. Porto: Afrontamento, 1995.

SAÚTE, Nelson. A guerra no imaginário moçambicano. Jornal de Letras, Artes e Ideias, n. 474, p. 5, 06 ago. 1991b.

SAÚTE, Nelson. Mia Couto. Escrevo por mãos de outros. Entrevista a Nelson Saúte. Jornal de Letras, Artes e Ideias, n. 475, p. 10-11, 13 ago. 1991a.

SEIXO, Maria Alzira. Olhares sobre o mundo: A Varanda do Franzipani. In: SEIXO, Maria Alzira. Outros Erros. Ensaios de Literatura. Porto: ASA, 2001.

SPIVAK, Gayatri. A Critique of Postcolonial Reason. Massachusetts: Harvard Press University, 1999.

VENTURA-Susana Ramos. Terra sonâmbula e $O$ outro pé da sereia: dois marcos na obra do romancista Mia Couto. In: Navegações, Porto Alegre, v. 6, n. 2. p. 219-227, jul./dez. 2013. Disponível em: <http://revistaseletronicas.pucrs.br/ojs/ index.php/navegacoes/article/view/16794>. Acesso em: 22 jun. 2015.

ZARUR, Cristina. O prazer quase sensual de contar histórias. O Globo. Rio de Janeiro, 30 jun. 2007. Disponível em: $<$ https:// flip2007.wordpress.com/2007/06/30/o-prazer-quase-sensualde-contar-historias-entrevista-com-mia-couto/>. Acesso em: 12 jun. 2015.

Recebido: 15 de setembro de 2016 Aprovado: 25 de maio de 2017 Contato: oribeiro@utad.pt fmoreira@utad.pt 